\title{
Estrategias de enunciación en la literatura del siglo XVI: algunos ejemplos en la caballería literaria
}

\author{
Enunciation Strategies in 16th Century Literature: \\ Some Examples in Literary Chivalry \\ Susana Gil-Albarellos Pérez-Pedrero \\ (Universidad de Valladolid)
}

\section{RESUMEN}

Este trabajo muestra una visión de conjunto de las diversas y complejas formas de enunciación utilizadas por los autores de los libros de caballerías durante el siglo XVI, analizando algunos ejemplos representativos de los mismos. La difusión de la materia caballeresca gracias a la expansión de la imprenta, al éxito de las propias obras literarias y a la confusión entre la dualidad historia y ficción, favoreció que los autores reales se hicieran pasar por traductores o editores de los textos. Junto a esta circunstancia, otros libros de caballerías aparecieron bajo el anonimato, posiblemente por autoría femenina, y otros, al fin, fueron víctimas de la impostura. En definitiva, el género caballeresco puso en marcha todo un juego de autores y narradores que anticiparon y abrieron el camino a la consolidación de la novela por parte de Cervantes con el Quijote.

\section{Palabras Clave}

Libros de caballerías, autores, narradores, historia y ficción, anonimato, impostura.

\begin{abstract}
This work shows an overview of the diverse and complex forms of enunciation used by the authors of the books of chivalry during the sixteenth century, analyzing some representative examples of them. The dissemination of chivalric material thanks to the expansion of the printing press, the success of the literary works themselves and the confusion between the duality of history and fiction favored the real authors to impersonate translators or publishers of the texts. Alongside this circumstance, other books of chivalry appeared under anonymity, possibly by female authorship, and others, at last, were victims of the imposture. In short, the chivalrous genre launched a whole set of authors and narrators who anticipated and opened the way for the consolidation of the novel by Cervantes with Don Quijote.
\end{abstract}

\section{KeYWORDS}

Chivalry books, Authors, Narrators, History and fiction, Anonymity, Imposture. 
Recibido: $29 / 07 / 2020$

Aceptado: 02/10/2020

La teoría de los géneros literarios en la actualidad, especialmente la referida a la narrativa, se ha ido formando esencialmente a través del descubrimiento de las pautas de construcción de las obras en prosa de Cervantes, en primer lugar del Quijote, pero también del Persiles y de las Novelas ejemplares, puesto que en su estudio, nunca concluido, por medio del análisis y del cotejo, se hallan las técnicas de construcción del género que llamamos novela. Quiso Cervantes explorar minuciosamente las posibilidades que ofrecían al escritor los tres pilares bajo los que se sustenta cualquier obra y su definición genérica -el autor, la propia obra y el lector-, en una literatura original pero abarcadora de la narrativa anterior.

Después de numerosos estudios individuales, una visión de conjunto a través de algunos ejemplos de cómo las formas en que se presentan los autores y narradores en obras significativas de la narrativa de caballerías durante el siglo XVII pudieron influir en la construcción del Quijote y, por tanto, en la formación y consolidación de la novela en su sentido actual, se hace necesaria para valorar también las diferentes formas en las que la enunciación narrativa se ha desenvuelto hasta nuestros días. Autores, editores, falsificadores, así como traductores, o sabios encantadores no son sino estrategias de enunciación que tienen que ver en último caso con la compleja frontera entre la historia y la ficción y con el pacto narrativo desde el punto de vista pragmático. Cervantes delimita la responsabilidad de la escritura de ficción y las posibilidades de su exposición dentro del ámbito interno de la narración, puesto que las presenta todas: Cervantes escritor imagina a un personaje, Cide Hamete, cuya obra traducida relata Cervantes narrador. Este juego de voces, que comienza en el capítulo 7 de la primera parte y que se mantendrá a lo largo de las dos partes del Quijote, se vio alimentado, ya en la segunda, gracias a la publicación en 1614 del Quijote de Avellaneda. Del género caballeresco Cervantes no sólo extrae el trasunto paródico de la historia que cuenta, sino también técnicas narrativas que tienen su antecedente en las diversas formas de autoría de la narrativa caballeresca para, en un ejercicio admirable de intertextualidad, superarlas.

Durante el siglo XVI en España los libros de caballerías forman un conjunto heterogéneo de textos que, sin embargo, presentan rasgos uniformes que permiten considerarlos como género literario preciso dentro de la narrativa de ficción. Su definición teórico-genérica es compleja por manifestarse en un momento de transición entre las formas narrativas medievales y la novela moderna, que tiene su referente en el Quijote. Cronológicamente, las narraciones que forman el género se escriben en un período de tiempo que abarca aproximadamente un siglo, desde 1508 con Amadís de Gaula, en la refundición de Montalvo, hasta el siglo XVII con la última continuación de Espejo de príncipes y caballeros de 1623. El género gozó de una amplia aceptación por parte del público y todo tipo de lectores se acercó con interés a las aventuras literarias de los caballeros andantes, desde la aristocracia hasta el pueblo, gracias a la imprenta que jugó un papel decisivo en su consolidación y favoreció tanto su desarrollo que se convirtió en un negocio para autores y editores.

El estudio de los libros de caballerías se ha centrado generalmente en el análisis de sus elementos argumentales y formales, así como en sus repercusiones en el ámbito literario y cultural, pero hay otros puntos que afectan de manera fundamental a su definición genérica y que tienen que ver con tres elementos sustanciales, que además están estrechamente relacionados. En primer lugar, la generalización del uso de la imprenta, que permite dar a conocer a más público y mejor las 
novelas. Unido a ello y como segundo tema, la difusión -y en ocasiones, asunción- de las teorías aristotélicas en torno al concepto de mímesis, matizadas o erróneamente interpretadas por los comentaristas durante el siglo XVI, que condicionan la forma y el contenido de las obras; $y$ en tercer lugar, la cuestión de la autoría de los libros de caballerías en la Península Ibérica, puesto que su escritura coincide cronológicamente con los cambios fundamentales que en torno a concepto de «autor»y «artista» se empiezan a vislumbrar en los albores del Siglo de Oro. Estos tres factores delimitan lo escrito por los autores de narrativa caballeresca en España, los definen como escritores de ficción y explican los intentos de justificación de su tarea literaria.

La invención de la imprenta, pocos años antes del desarrollo pleno del género caballeresco en España, es un acontecimiento a tener en cuenta para entender el éxito que sin duda tuvieron estas ficciones, ya que al tiempo que favoreció su difusión, también provocó su censura. Al mismo tiempo, esta forma de censura o crítica, que culmina en el escrutinio cervantino del capítulo 6 de la primera parte del Quijote, es también causa del problema de confusión en cuanto a la autoría de alguna de las principales novelas caballerescas, puesto que unido al juego de enunciación, revela un deseo por eludir el compromiso con lo escrito, de manera que en la consolidación de la novela moderna a partir de la narrativa en el siglo XVI, la de caballerías va a suponer, por todas las razones apuntadas, un pilar fundamental.

La preocupación por la responsabilidad del texto escrito surge especialmente a partir del Renacimiento y no sólo desde el punto de vista de su papel en el ámbito cultural, sino también en el aspecto económico y de protección jurídica. En este sentido, Burke señala que ello es consecuencia del reconocimiento social de pagar por el conocimiento que posee el maestro y evitar las continuas disputas por acusaciones de plagio; de esta forma comienza la idea de que el conocimiento es también mercancía que se puede vender y que tiene por tanto derecho de propiedad:

Durante la Edad Media, la acción de «compilar»-o recopilar- se convirtió en algo respetable, lo que indicaría que el sentido de propiedad intelectual perdía nitidez. Lo cierto es que durante el siglo XIII el argumento legal tradicional según el cual el conocimiento era «un don de Dios que no puede venderse» fue puesto en tela de juicio por el nuevo principio según el cual los profesores merecían recibir una paga por su trabajo... Durante el Renacimiento, las disputas sobre los plagios se hicieron cada vez más frecuentes, a pesar de (o debido a) la dificultad de definir la propiedad intelectual. Los humanistas del Renacimiento se acusaban regularmente unos a otros de «robo», aunque todos afirmaban practicar simplemente una forma de «imitación» creativa... Escritores e impresores se disputaron entre sí los derechos de propiedad sobre el texto. Tales disputas habría que relacionarlas con el «individualismo», la emulación y la autoconciencia de que habló Jacob Burckhardt en su famoso libro La cultura del Renacimiento en Italia (1860). Están conectadas con la génesis de la idea de «genio», con los orígenes de la « originalidad», el declive del concepto de «autoridad»y el «nacimiento de autor». Esas disputas revelan, además, cambios en el equilibrio entre monopolio y competencia en el campo del conocimiento (Burke, 2002: 194-195).

Junto al amplio despliegue en el uso de la imprenta se constata un claro declive en el número de documentos anónimos debido a la creciente profesionalización de la escritura. En consecuencia, se consolida el hecho de que cada autor se ve obligado a responsabilizarse de sus escritos, teniendo en cuenta que esa responsabilidad en la firma de los textos de cada uno conlleva, en el peor de los casos, la condena, pero también la posibilidad de alcanzar la fama gracias a ellos. Estas 
nuevas condiciones en las que se sitúa el autor en cuanto a su compromiso con los textos que escribe podrían justificar en parte que los libros de caballerías castellanos escritos en el siglo XVI en muchas ocasiones vieran la luz sin nombre de autor, o al menos silenciando su identidad o bien escondiéndola bajo la rúbrica de una falsa traducción o el nombre de un antiguo personaje, que figura intratextualmente como el auténtico creador del texto.

Así pues, a partir de la difusión de la imprenta se produce el cambio en la constitución del libro y en el concepto e importancia del autor. Pero no sólo es esa circunstancia de carácter técnico lo que determina la función del autor, sino muy especialmente otro problema planteado desde el siglo XV en España en el ámbito de la creación literaria. Los escritores de libros de caballerías, conscientes en todo momento de la complejidad de los límites entre historia y ficción, se afanan en solucionar el dilema de esa dualidad mediante mecanismos estructuradores del relato. Sabemos que en el momento de su publicación muchos lectores no tuvieron clara la interpretación de esta literatura como ficción e intentaron autentificarla siguiendo los propósitos que los propios autores declaraban en sus mismos textos, en los que se presentaban como traductores o editores de obras escritas en otras lenguas y halladas en lejanos reinos, producto de revelaciones durante sueños fantásticos. De ahí que la conocida polémica suscitada en torno a las licencias de la ficción afectase también a la función de los autores reales de los textos en cuanto a su responsabilidad en la escritura de los mismos, y a la más que probable confusión entre autor-narrador, creador-traductor-refundidor, que más tarde tan bien aprovecharía Cervantes. Con ello quiero insistir en la idea de que las diversas maneras en las que estos autores se presentan durante la primera mitad del siglo XVI es consecuencia de ese cambio en la forma de entender los límites de la mímesis, y en definitiva, la forma de concebir el propio arte literario, como arte y como ficcional, en la escritura de unas narraciones herederas de los romans medievales. El juego cervantino en la construcción del Quijote, en lo referido a la exposición de la historia a través de diversos narradores-traductores, así como la postura del propio Cervantes como autor real en la asunción total de compromiso ante su propia obra, tienen su antecedente claro en los distintos argumentos que los autores de la narrativa anterior, la de caballerías esencialmente, utilizan para demorar la responsabilidad en la escritura de los textos. Sin duda, el establecimiento de los límites entre la ficción y la realidad a partir del siglo XVI tiene su correspondencia práctica en la posición en la que se sitúan los autores reales al aparecer como padres, padrastros, editores, traductores o refundidores de sus obras.

Uno de estos recursos para reconciliar historia y ficción, quizá el más significativo, es el empeño de los autores por dotar de historicidad a sus narraciones, y ya se ve en Garci Rodríguez de Montalvo, que justifica en todo momento su quehacer, afirma haber corregido los tres primeros libros de Amadís de Gaula, y trasladado y enmendado el cuarto; es decir, se presenta como editor primero y como traductor, después. En cuanto a las Sergas de Esplandián, el recurso es de sobra conocido, ya que acude al tópico del manuscrito encontrado, y dice de este quinto libro que:

\footnotetext{
[...] hasta aquí no es en memoria de ninguno ser visto, que por gran dicha paresció en una tumba de piedra, que debaxo de la tierra en una hermita, cerca de Constantinopla fue hallada, y traído por un úngaro mercadero a estas partes de España, en letra y pargamino tan antiguo, que con mucho trabajo se pudo leer por aquellos que la lengua sabían. (Rodríguez de Montalvo, 2001, I: 224-225)
}

A estos esfuerzos por evitar la responsabilidad directa y soslayar la problemática historia y ficción, que se hacen explícitos desde el nacimiento del género caballeresco al presentarse como 
editores o traductores, se une muy pronto un tercero, el de los testigos presenciales que, bajo la rúbrica de que los hechos fueron vistos y oídos de primera mano por dichos testigos, aseguran su autenticidad. Este recurso es muy evidente en las Sergas de Espladián, que Montalvo afirma estar escritas por el sabio Elisabat, personaje desde la tercera parte de Amadís y «cronista» en las Sergas:

Aquí comienza el ramo que de los cuatro libros de Amadís sale, llamado Las Sergas de Esplandián, que fueron scriptas en griego por la mano de aquel gran maestro Elisabat, que muchos de sus grandes hechos vió y oyó, como aquel que, por el grande amor que a su padre Amadís tenía, se quiso poner en tan gran cuidado, y por ver sus grandes hechos en armas y le socorrer con sabiduría, como lo hizo en muchas partes donde mal herido fué. Las cuales Sergas después a tiempo fueron trasladadas en muchos lenguajes, según a las provincias y reinos donde llevarlas quisieron por donde a muchos manifiestas fuesen, que habiendo leído las grandes cosas del padre, con mucha afición las del hijo deseaban ver (Rodríguez de Montalvo, 1963: 403).

En las Sergas, además, el procedimiento se amplifica dentro de la propia narración cuando en los capítulos 98 y 99 el autor, que se confiesa cansado, decide concluir la narración del relato. Cuenta entonces cómo estando en su habitación fue transportado a una roca desde la que vio un barco con una doncella; esta doncella le llevó hasta su ama, Urganda la Desconocida, quien le traslada a Ínsula Firme, donde le insta a continuar su obra después de leer el libro de Elisabat. Urganda actúa aquí de intermediaria entre el mundo de las maravillas y el mundo real, interpolación y superposición de un mundo en otro, y es la colaboradora necesaria para que Montalvo, que se ha incorporado ficticiamente a su relato, justifique la incorporación de elementos ficcionales no verosímiles en su obra. Recordemos la corriente de humanistas y erasmistas que atacaba los textos ficcionales y se esforzaba en delimitar la frontera entre lo histórico y lo inventado, y preceptistas como Castelvetro, Torcuato Tasso, Luis Vives o Fray Luis de León, quienes siguen reclamando no sólo verosimilitud, sino la verdad de la historia.

Muchos son los que se han detenido en el análisis de estas estrategias narrativas que por recurrentes, son definitorias del género. En ellos, Marín Pina ha estudiado el recurso del «falso» traductor, tan habitual en los libros de caballerías españoles, o del editor, que ya desde los primeros representantes en la literatura española con Amadís van a ser tan frecuentes en el género, y señala cómo Montalvo de esta forma renuncia a la autoría del libro. (1994: 541-548; 2011).

Montalvo no es un caso aislado de autor de caballerías que se afana por dar visos de historicidad a su relato, hasta el extremo de poder afirmar que la recurrencia en el uso del manuscrito encontrado, del traductor, de las paternidades dudosas, del anonimato e incluso de la impostura, tienen que ver, en última instancia, con la configuración de la novela en su sentido moderno, proceso en el que la narrativa caballeresca se presenta como eslabón necesario. La pretensión de hacer creíbles las hazañas de los innumerables caballeros que pueblan nuestra narrativa caballeresca, en la que juegan un papel determinante los narradores, junto a las propias palabras de los autores vertidas en prólogos y dedicatorias, no son sino elementos estructuradores de una narrativa que se va alejando de las formas de los romans medievales. Y los escritores, identificados o enmascarados, convierten la enunciación en un juego de voces que si bien es heredero de las técnicas narrativas medievales de la literatura en lengua romance, anticipa y prepara el camino para las diversas y variadas formas de autoría de la narrativa contemporánea a través de Cervantes y el Quijote, porque al contrario que sus antepasados, son ya muy conscientes del valor diferenciado 
de la ficción frente a la historia, dotando así a sus narraciones de una independencia literaria frente a otras formas de escritura.

Conocedores de todos estos artificios narrativos creados con diversas finalidades, cabe preguntarse quiénes fueron los autores reales de los libros de caballerías, pues nos ayudará a comprender mejor su estrategia. Del autor del texto inaugural del género en nuestras letras, Garci Rodríguez de Montalvo, poco sabemos, ni siquiera está claro su nombre e incluso se han propuesto autorías portuguesas para el libro que reelabora (Sales Dasí, 1999: 123-158; Salvador Miguel, 2010: 245284). Parece inocente por parte de Cervantes no atribuir un nombre concreto a su hidalgo manchego, pero lo mismo sucede con Montalvo, puesto que en la primera edición de Amadís de Gaula (Zaragoza, 1508) se dice que el libro fue corregido y enmendado por «el honrado y virtuoso caballero Garci Rodríguez de Montalvo», mientras que en las ediciones sucesivas se firma Garci Ordóñez de Montalvo y, finalmente, en la edición de Roma (1525) de Las sergas de Esplandián, aparece como García Gutiérrez de Montalvo. Con todo, las referencias más fiables acerca de su persona se hallan en el prólogo de Amadís de Gaula y en Las Segas de Esplandián:

\begin{abstract}
De sí mismo bien poco nos dice Montalvo, ya sea en el Amadís o en Las sergas de Esplandián. De los preliminares del Amadís, y de carácter autobiográfico, sólo colegimos que era regidor de Medina del Campo y que escribía en la euforia de la reconquista de Granada. Más pródigo en alusiones personales es Montalvo en Las sergas de Esplandián, lo que no deja de ser apropiado, ya que se trata de su personal obra individual (Avalle Arce, 1990: 133).
\end{abstract}

No se saben con seguridad los datos de su biografía, aunque sí que debió de nacer a finales del reinado de Juan II de Castilla y que conoció la conquista de Granada en 1492. Otras noticias las poseemos gracias a Narciso Alonso Cortés, quien encontró en la Chancillería de Valladolid un pleito que siguieron los parientes del autor, por el que sabemos que en 1505 ya había fallecido y que tuvo tres hijos que se mencionan por nombre: Pedro Vaca, Juan Vaca Montalvo y Francisco Vaca (1933: 434). Probablemente fue un hombre de cierta relevancia, cercano a la corte. Otros investigadores han propuesto otros datos autobiográficos más arriesgados pero igualmente interesantes, como William Thomas Little, quien insiste en una teoría ya enunciada -y otras tantas veces desautorizada-, según la cual Montalvo era converso, circunstancia que explicaría en gran medida sus juegos de ocultamiento:

Las voces narrativas de Montalvo se contradicen con tanto arte y con tanta frecuencia precisamente porque el único método de que disponía un escritor converso para inmortalizarse en la España de fines del siglo XV era el discurso subversivo (Little, 2002: 196).

La pregunta, en cualquier caso, es por qué un regidor de la muy importante villa de Medina del Campo a finales del siglo XV se lanzó a tan magna empresa de corregir los cuatro libros de Amadís y añadir un quinto. Varias son las respuestas. En primer lugar, la afición a la temática caballeresca, que había llegado a la Península con cierto retraso con respecto a sus parientes franceses, pero que estaba encaminada a convertirse en un auténtico filón literario, y por otro, la idea de la importancia de la fama asociada al caballero durante la Edad Media, traspasada ahora a la imperecedera ansia de inmortalidad a través de las letras: «desseando que de mí alguna sombra de memoria quedasse», afirma en el prólogo de Amadís. Unido a estas dos, otra de carácter más político, siguiendo las Sergas: 
[...] nuestro refundidor habría podido conocer a personajes significativos de la corte regia y haberse sentido estimulado a reescribir el Amadís como tributo particular a los ideales y las prácticas de un nuevo espíritu caballeresco (Mérida Jiménez, 1999: 182).

Y si poco se sabe de Montalvo, no contamos con más información del autor del Palmerín de Olivia, primer libro de la saga de los palmerines y significativo en el caso que nos ocupa porque se presenta como anónimo y se sospecha de autoría femenina, al menos en alguna de sus partes. De hecho, ambas circunstancias están relacionadas. No existen suficientes apoyos documentales para afirmar con seguridad que la obra fuera escrita por una mujer, aunque ayudada por su hijo en algunas partes, hipótesis basada en que a partir de cierto momento, al cambiar de mano, cambia también el estilo y el tono de las aventuras.

El origen de la atribución femenina compartida por su hijo parte de la primera edición del texto en 1511. En la composición de Juan Augur de Trasmiera que cierra el libro, en los versos $45 \mathrm{y}$ 46 se lee: Femina composuit; generosos atque labores / filius altisonans scripsit et arma libro; y por esa cita, ha cobrado fuerza la tesis de la autoría por parte de una mujer, teniendo en cuenta que Juan Augur era, además, asesor en la imprenta de Porras, responsable de que Palmerín y Primaleón vieran la luz. Ya Menéndez Pelayo en sus Orígenes de la novela, hablando de este libro y del Primaleón, niega el origen portugués de los autores (1943: 415). En el prólogo del Palmerín de Olivia, de Salamanca de 1511, así como en la edición sevillana de 1524 del Primaleón, se habla de que ambos libros fueron «trasladados de griego en nuestro lenguaje castellano, corregidos y emendados en la muy noble cibdad de Ciudarrodrigo por Francisco Vazquez, vecino de la dicha ciudad», pero, ¿tuvo alguna responsabilidad en los textos o efectivamente sólo fue el traductor y corrector de los mismos? Don Marcelino se cuestiona la participación de Francisco Vázquez, tal vez el hijo que ayudara a la autora en la construcción principalmente de los hechos de armas, y concluye que «lo que parece fuera de duda es el origen femenino de la obra». En ediciones posteriores, como la de 1534 de Venecia, corregida por Francisco Delicado, se afirma que quien la compuso «era muger, y filando el torno se pensaua cosas mas fermosas, que dezia ala postre, y fue mas enclinada al amor que alas batalias, a las quales da corto fin. [...] Y es opinión de personas que fue muger la que lo compuso, fija de un carpintero».

Aun así, la referencia en el prólogo de Primaleón a Francisco Vázquez como traductor y enmendador de ambos textos, de éste y del Palmerín, ha llevado a la crítica a conjeturar la posibilidad de que sea el verdadero autor de las obras, o por el contrario, que sea el hijo que ayudó a su madre en la composición. Efectivamente, en el Primaleón se advierte de que esta obra y el Palmerín son traducciones del griego, nada extraño por otro lado en la configuración del género caballeresco. Con estos datos, como antes he advertido, nada hasta la fecha prueba o desmiente la tesis femenina en la composición de la obra, puesto que lo señalado en los prólogos, o en los versos finales de Juan Augur, pueden no ser sino estrategias de un autor real escondido, masculino o femenino, por atractiva que dicha atribución sea para la historia del texto y en general de la literatura española, puesto que de ser cierta, nos encontraríamos con el primer caso conocido de una autora de ficción en nuestras letras.

Además del Palmerín de Olivia, es casualmente otro libro de caballerías el que ostenta el honor de haber sido escrito por una mujer, y ahora sin duda respecto a su identidad. Me refiero a Beatriz Bernal, autora de Don Cristalián de España, publicado en el año 1545 y cuyo título completo es Historia de los invictos y magnánimos cavalleros don Cristalián de España, príncipe de Trapisonda, y del infante Luzescanio su hermano, hijos del famosíssimo emperador Lindedel de Trapisonda. La figura de 
Beatriz Bernal debe ser reseñada porque se trata de la primera autora de ficción en nuestras letras ${ }^{1}$. Su nombre, como no podía ser de otra manera en aquella primera mitad del siglo XVI, no aparece en la portada, ya que no estaba bien visto que la mujer se dedicara a la escritura de ficción. Sin embargo, existen datos históricos de carácter legal para la confirmación de la autoría, como ha demostrado Anastasio Rojo, quien, en «Manuscritos y problemas de edición en el siglo XVI», relata cómo la autora pidió licencia de impresión en 1537 de «un libro de caballerías que compuso una mujer», y cómo el encargado de la revisión del texto, el doctor Busto, se mostraba contrario a este tipo de libros, pero puesto que los demás se habían impreso, no contó con ningún mal añadido para impedir su impresión. Posteriormente su hija, ya fallecida la madre, volverá a pedir la licencia para la reimpresión y en la segunda edición, de 1587 ya figura su nombre en la portada.

Con otra forma de mostrar sus verdaderas identidades y personalidades se muestran Feliciano de Silva en su Amadís de Grecia, publicado en 1534, y Antonio de Torquemada en el Prólogo a su Don Olivante de Laura, cuya única edición conocida data de 1564 en Barcelona. Feliciano de Silva (hacia 1486-1554), nombre real del autor de varios libros de caballerías, además de la Segunda Celestina, publicada en 1534, fue hijo de Tristán de Silva, cronista de Carlos V, regidor de Ciudad Rodrigo; sabemos que quizá estuvo al lado del Emperador en la Guerra de los Comuneros, y parece que viajó a Sevilla y a América. En cualquier caso, el pobre Feliciano, que desde sus contemporáneos pasando por Cervantes y terminando en Menéndez Pelayo -quien dijo de él: «[h] ombre de fácil pluma, de mediano ingenio, de fantasía superficial y desordenada, y de mucha aunque mala invención» (407), no ha dejado de sufrir las críticas más enervadas por su quehacer literario, también se preocupó, y mucho, por establecer ese juego literario que ya en Amadís fue dispuesto para el género caballeresco y que consiste en eludir la autoría directa de los textos presentando las ficciones producto de su invención como traducciones o revelaciones. Es especialmente sugerente la argucia narrativa perpetrada en su Amadís de Grecia, de 1530, segunda de sus continuaciones de Amadís. La obra está dedicada a don Diego de Mendoza, duque del Infantazgo, conde del Real, marqués de Santillana, señor de las Casas de la Vega, con la siguiente justificación, expuesta en el prólogo:

Porque, sin pensar, a mi poder vino que fue esta gran corónica del valiente y esforçado Amadís de Grecia; la cual en estraña lengua con la antigüedad del todo se perdiera si con la afición que a sus padres tuve, que con no menos trabajo su corónica en mi niñez passé y corregí, la suya no corrigiera y sacara (2004: 4).

En esta obra se introduce el elemento pastoril (Segunda Parte, caps. 131-134) cuando para conseguir el amor de Silvia, el doncel Florisel de Niquea se convierte en pastor. Sin embargo, lo interesante para la estrategia de incorporar la ficción bajo el manto de lo verosímil y, al mismo tiempo, el ocultamiento de la autoría, es que entre la primera y segunda parte del Amadís de Grecia, Feliciano de Silva introduce un fragmento en dos piezas, titulados respectivamente «Lamentación»y «Sueño», que constituye un injerto de la ficción sentimental en la caballeresca, híbrido genérico que ya se halla en el Tristán de 1501, como demostró Sharrer (147). En el segundo de ellos, «Sueño», asistimos al catálogo de normas que rigen el comportamiento del ferviente enamorado y a cómo al final el soñador, en primera persona, despierta a la vida real, la del traductor,

1. Para una completa información de Beatriz Bernal y de su obra es fuente imprescindible la tesis doctoral de Gagliardi que con el título «Quid puellae cum armis?». Una aproximación a Doña Beatriz Bernal y a su Cristalián de España fue leída en la Universidad Autónoma de Barcelona en 2003 (https://www.tdx.cat/handle/10803/4868\#page=1). Véase Gagliardi (2010) como libro resultante de esta tesis. 
con lo que la interacción ficción / realidad se ha forjado a través del sueño del traductor, pues como tal se presenta la obra:

Y, no perezoso en saber el fin de mi desseo fui allí donde me mandó que la buscasse y la hallaría, y hallela tal por la gran antigüedad, que con el desseo pude acabar de sacar la obra que el gran trabajo me vedava, esforçándome para que tal comienço no quedasse sin la segunda parte de tan enxalçado fin; la cual sacada y traduzida de latín empieça en esta manera (2004: 247).

Ante esta circunstancia cabe preguntarse, como hace Brandenberger: $\ll_{i}$ Quién es esta primera persona que al principio se lamenta y después sueña? La pregunta nos lleva directamente al problema de las instancias narrativas y del estatuto del autor» (2003: 66). De donde concluye:

La ilusión de un relato que representa y actualiza un pasado lejano se quebranta; pero por otro lado, la credibilidad de los tópicos usuales se ve apoyada cuando el «traductor» se hace oír con una historia que se pretende autobiográfica, insertándola en el texto de otra obra, aparentemente también de su incumbencia (en cuanto «traductor»), fortaleciendo así la autenticidad de la ficción (2003: 68).

Es el ejemplo más llamativo, puesto que demuestra los ingentes esfuerzos por retorcer, por distintos caminos narrativos y por diferentes causas, las instancias narradoras y su relación con los autores reales que repetidamente aparecen en los libros de caballerías, entre otras razones, porque el «Sueño» de Feliciano de Silva se ha visto como relato autobiográfico en el que cuenta su relación con Gracia de $\mathrm{Fe}$, con la que el autor casó.

Por su parte, en el «Prólogo del auctor» de Olivante de Laura, Antonio de Torquemada cuenta un extraño viaje subterráneo en el que, tras diversas aventuras y apariciones de personajes tanto reales como ficticios, le es encargado por parte de la sabia Ypemea el arreglo y divulgación del libro donde se cuentan los hechos de su protegido Olivante de Laura:

aquí te he hecho venir para rogarte que tengas por bien recebir un libro en el qual, con entera verdad, yo sus supremos y valerosos hechos, no añadiendo mas antes quitando de lo que deviera, hize escrevir, para que con toda diligencia, poniéndolo en el estilo más primo de la lengua que agora se usa, lo mejor que tú pudieres lo hagas divulgar y publicar, como a noticia de todas las gentes venga. Porque yo confío de tu saber y diligencia, que en lo que te encargo y encomiendo, no aviendo falta en la voluntad, no la avrá en lo que te pido (1997: 28).

Torquemada acepta el encargo, tras lo cual se despierta con el libro entre las manos, probando que todo es realidad, y no sueño ni visión. Con ello el autor, al igual que hiciera Montalvo, se convierte en divulgador de una obra escrita por «historiadores» que se pierden en los tiempos, afianzando la intencionada veracidad del relato.

La falsa autoría, junto a la ocultación, recursos tan habituales en la literatura a partir del siglo XVI, son estrategias de enunciación que encontramos en la obra de Antonio de Torquemada. Rodríguez Cacho ha trazado la historia casi policíaca de la impostura, que se resume con los siguientes datos: Don Olivante de Laura apareció anónimo en 1564 y con una dedicatoria del impresor barcelonés Claudio Bornat a Felipe II, en la que aseguraba haberla traducido del griego (1989: 
515). A partir de entonces y durante más de veinte años, la novela circuló anónima, y con lectores aventurando distintas autorías hasta que en 1585, en documentos aparecidos en el Archivo Histórico de Protocolos de Madrid, los hijos de Torquemada intentan conseguir el reconocimiento legal de sus derechos sobre la edición y venta de la novela, que habría sido robada a su padre una vez muerto. En otro de los documentos, Luis de Torquemada (hijo) lega los derechos de las obras a su hermano Jerónimo de los Ríos. Parece que el manuscrito fue robado por el toledano Alonso del Castillo de Lira y acabó en las manos del editor, que vio en esa impostura una posibilidad de lucro. El robo se debió sin duda a la popularidad de las obras de Torquemada (Jardín de flores curiosas) y de la temática caballeresca, pero lo que es interesante, como ha demostrado Rodríguez Cacho, es que mucho antes de encontrar esos documentos legales - pues se han hallado en el siglo $\mathrm{XX}-$, Cervantes ya sabía quién era el autor:

- ¿Quién es ese tonel? -dijo el cura.

- Éste es -respondió el Barbero-Don Olivante de Laura.

- El autor de ese libro -dijo el cura- fue el mesmo que compuso a Jardín de flores; y en verdad que no sepa determinar cuál de los dos libros es más verdadero, o, por decir mejor, menos mentiroso; sólo sé decir que éste irá al corral, por disparatado y arrogante [I, 6] (1998: 78-79).

A partir de estos y otros ejemplos se puede asegurar que en el proceso de consolidación del género caballeresco eran muchos los problemas de índole semántico y formal que los autores debían resolver, y que tenían que ver, entre otros de carácter literario, con su identidad y la responsabilidad de sus propios escritos dentro de la república de las letras en los albores del siglo XVI. Son tales los excesos de imaginación que aparecían en los libros a partir de las continuaciones de Amadís y Palmerín, que inevitablemente también había que salvar las posibles críticas que su lectura iba a desencadenar, como así fue. Por ello, ahora desde la perspectiva de un lector del siglo XXI, es fácil comprender los distintos caminos por los que estos autores se «esconden»o que cuando firman, justifican sus escritos. Sin embargo, en estas líneas me he centrado en algunos problemas de autoría en las obras inaugurales de los ciclos principales de caballeros andantes, en concreto en el caso de Amadís de Gaula y de Palmerín de Olivia, y ello porque ambos son casos significativos, si bien por distintas razones.

En Amadís sí sabemos la autoría a cargo de Garci Rodríguez de Moltalvo, pero también de la existencia de manuscritos medievales del texto que pudo conocer y refundir, entendiendo este concepto de autor en sentido medieval, es decir, en un sentido muy amplio. Además, como he señalado, hay pocos datos fiables de su biografía, de manera que es difícil decidir qué parte es enteramente invención y qué parte es refundición, todo ello contando con que se presenta como editor o como traductor de la obra e incluso se «ficcionaliza» en su propio texto. En el caso de Palmerín de Olivia, en cambio, estamos ante un caso de anonimato, muy característico de la literatura medieval, que tendría pleno sentido si efectivamente el libro hubiera sido escrito por una mujer. En cualquier caso, ambas son autorías difíciles por las muchas circunstancias de índole histórico-literaria que les rodean, además en fecha muy temprana para el género ( 1508 y 1511, respectivamente).

Sin embargo, en los siguientes juegos de enunciación con respecto a los autores reales -aun cuando conozcamos sus identidades- que aparecen en las novelas de caballerías que siguen estos dos modelos, se deben posiblemente a un ejercicio de imitatio de los patrones primeros, y al 
hecho de que ya en el momento de su redacción, las críticas por parte de los humanistas y de la iglesia eran generalizadas. Mención aparte merece el caso del robo de Don Olivante de Laura, completando con esta falsificación las formas en los que los autores de caballerías revelan su identidad. En resumen, los avances técnicos debidos principalmente a la expansión de la imprenta, el cambio de mentalidad que supone la valoración del escritor y su responsabilidad en lo escrito, así como los condicionantes que las preceptivas imponen y que son causa de las críticas a esta literatura, son los motivos más señalados de la confusa situación en la que se presentan los autores de los libros de caballerías durante el siglo XVI. Una situación que tiene más trascendencia de la que podría parecer en la configuración del género, y lo define en su configuración hacia la moderna teoría de la novela.

\section{Bibliografía}

Alonso Cortés, Narciso (1933), «Montalvo, el de Amadís». Revue Hispanique, LXXXI, pp. 434-442.

Avalle-ArCe, Juan Bautista (1990), Amadís de Gaula: el primitivo y el de Montalvo. México, FCE. BrANDENBerger, Tobías (2003), «Libros de caballerías y ficción sentimental: el taller de Feliciano de Silva», Revista de literatura medieval. 25, 1, pp. 55-80.

Burke, Peter (2002), Historia social del conocimiento. De Gutenberg a Diderot. Barcelona, Paidós.

Cervantes, Miguel de (1998), El ingenioso hidalgo Don Quijote de la Mancha, Barcelona, Crítica.

GAGLIARDI, Donatella (2010), Urdiendo ficciones: Beatriz Bernal, autora de caballerías en la España del XVI, Zaragoza, Prensas Universitarias de Zaragoza.

Litrle, William Thomas (2002), «Notas preliminares para unos textos subversivos de Garci Rodríguez de Montalvo, ¿converso?», Dicenda, 20, pp. 157-196.

Marín Pina, María del Carmen (1994), «El tópico de la falsa traducción en los libros de caballerías españoles», en Actas del III Congreso de la Asociación Hispánica de Literatura Medieval, ed. María Isabel Toro Pascua, Salamanca, Univ. de Salamanca, pp. 541-548.

(2011), Páginas de sueños. Estudios sobre los libros de caballerías castellanos, Zaragoza, Institución 'Fernando el Católico' (Diputación de Zaragoza).

Menéndez Pelayo, Marcelino (1943), Orígenes de la novela, Madrid, CSIC.

MÉRIDA JimÉnez, Rafael M. (1999), «Las historias fingidas de Garci Rodríguez de Montalvo», Thesaurus. 54, 1, pp. 180-216.

Muguruza Roca, Ma . Isabel (1991), «Sobre el prólogo de Don Olivante de Laura, de Antonio de Torquemada», en Evolución narrativa e ideológica de la literatura caballeresca, ed. M. ${ }^{\text {E }}$. Lacarra, pp. 127-144.

Palmerín de Olivia (2004), ed. Giuseppe di Stefano. Alcalá de Henares, Centro de Estudios Cervantinos.

Primaleón (1998), ed. M. ${ }^{a}$ Carmen Marín Pina, Alcalá de Henares, Centro de Estudios Cervantinos.

Rodríguez CACHo, Lina (1989), «Don Olivante de Laura como lectura cervantina: dos datos inéditos $\gg$, en Actas II Congreso de la Asociación de Cervantistas, pp. 515-525.

Rodríguez de Montalvo, Garci (1963), Las sergas de Esplandián, ed. Pascual de Gayangos. Madrid, 'BAE', 40. (2001), Amadís de Gaula, ed. Juan Manuel Cacho Blecua, Madrid, Cátedra, 2 vols. 
Roubaud-BÉnichou, Sylvia (2000), Le roman de chevalerie en Espagne, entre Arthur et Don Quichotte, Paris, Champion.

Sales Dasí, Emilio José (1999), «Garci-Rodríguez de Montalvo, regidor de la noble villa de Medina del Campo», Revista de filología española, 79, fasc. 1-2, pp. 123-158.

Salvador Miguel, Nicasio (2010), «Garci Rodríguez de Montalvo, autor del Amadís de Gaula», en Actas XIII Congreso AHLM, Valladolid, Universidad de Valladolid, pp. 245-284.

SHARRER, Harvey (1984), «La fusión de las novelas artúrica y sentimental a finales de la Edad Media», Crotalón, 1, pp. 147-157.

Silva, Feliciano de (2004), Amadís de Grecia (IX), ed. Ana Carmen Bueno Serrano y Carmen Laspuertas Sarvisé, Alcalá de Henares, Centro de Estudios Cervantinos.

Torquemada, Antonio de (1997), Obras completas. 2, Don Olivante de Laura, Madrid, TurnerBiblioteca Castro.

Williamson, Edwin (1991), El Quijote y los libros de caballerías, Madrid, Taurus. 